\title{
Poison frog dietary preference depends on prey type and alkaloid load
}

\author{
Nora A. Moskowitz, Rachel D’Agui, Lauren A. O’Connell* \\ Stanford University, Department of Biology, 371 Jane Stanford Way, Stanford, CA 94305
}

Running title: Poison frog prey preference

*Where correspondence should be addressed:

Lauren A. O'Connell

Department of Biology

Stanford University

371 Jane Stanford Way

Stanford, CA 94305

loconnel@stanford.edu

Number of Tables: 2

Number of Figures: 4

Word count: Abstract: 239; Main text: 5850

Keywords: predation, feeding ecology, foraging behavior, decahydroquinoline, arthropods 


\begin{abstract}
The ability to acquire chemical defenses through the diet has evolved across several major taxa, including insects, mollusks, birds and reptiles. Chemically defended organisms may need to balance chemical defense acquisition and nutritional quality of prey items. However, these dietary preferences and potential trade-offs are rarely considered in the framework of diet-derived defenses. Poison frogs (Family Dendrobatidae) acquire defensive alkaloids from their arthropod diet of ants and mites, although their dietary preferences have never been investigated. We conducted prey preference assays with the Dyeing Poison frog (Dendrobates tinctorius) to test the hypothesis that alkaloid load and prey traits would influence dietary preferences. We tested size preferences (big vs. small) within each of four prey groups (ants, beetles, flies, and larvae) and found that frogs generally preferred interacting with smaller prey items. Frog taxonomic prey preferences were also tested as we experimentally increased their chemical defense load by feeding frogs decahydroquinoline, an alkaloid compound similar to those naturally found in their diet. Contrary to our expectations, overall preferences did not change during alkaloid consumption, as frogs across groups preferred larvae over other prey. Finally, we assessed the protein and lipid content of prey items and found that small ants have the highest lipid content while large larvae have the highest protein content. Our results suggest that consideration of toxicity and prey nutritional value are important factors in understanding the evolution of acquired chemical defenses and niche partitioning as a whole.
\end{abstract}




\section{Introduction}

Animals must make efficient use of available food to satisfy their energetic and nutritional demands that are necessary for day-to-day function, reproduction, and survival (1). Optimal foraging theory predicts that organisms forage to maximize fitness by reducing the energetic costs associated with consuming low quality prey (1). Chemically defended animals across many taxa acquire toxins through their diet, and therefore their foraging decisions should be based on both chemical defense acquisition and nutritional quality of prey items. Most studies on organisms with acquired chemical defense focus on cataloging prey items from stomach contents, such diet studies in bufonid (Melanophyriniscus) toads, Pitohui birds and Natricine snakes (2-4). However, quantification of prey availability and nutritional content are rarely considered, leaving a gap in our current understanding of how dietary preferences evolve within the context of acquired chemical defenses. Examining how prey availability and nutritional value may influence selection of prey items contributes to our general understanding of community ecology and the evolution of acquired chemical defense.

Generalist predators must strike a balance between the energetic costs of foraging and prey nutritional value and availability $(5,6)$. For example, Schizocosa wolf spiders make choices based on their nutritional and energetic demands by selecting for certain prey, even if they are low in abundance in their environments (7). Some predators must further consider the physiological burden of prey ingestion, especially in species that regularly consume chemically defended prey items. For example, the European Starling (Sturnus vulgaris) can learn to avoid toxic prey, but still choose to ingest them in the presence of undefended prey (8). This suggests that defended prey are worth consuming despite their physiological burden, as they may be nutritionally valuable (8). Such a nutritional tradeoff has also been proposed in possums, which regularly consume chemically defended plants that are metabolically costly but nutritionally valuable (9). Choice of prey is arguably even more complex in organisms that acquire chemical 
defenses from their prey items. For example, Acalymma vittatum beetles have diet-derived chemical defenses and there is a tradeoff between protection from predators and the physiological costs of detoxification (6). These choices are not only important for short term energy needs, but they can also impact development and have long lasting consequences on fitness. In Battus philenor butterflies, sequestering defensive chemicals from plants increases survivorship against predation as caterpillars, but at the cost of reduced fat content as adults (5). Together, these examples suggest that environmental availability, chemical defense, and nutritional content of prey items are important considerations for predators with diet-derived defenses $(2,3,10)$. However, the interplay between these factors in foraging decisions made by animals that acquire chemical defenses from their diet is poorly understood.

Diet-derived chemical defenses have evolved multiple times in Central and South American poison frogs (Dendrobatidae), which acquire alkaloid-based chemical defenses from their diets $(11,12)$. Chemical defenses have evolved at least four times within Dendrobatidae, which co-evolved with a dietary specialization on ants and mites in some species $(13,14)$. Stomach content analyses have established that alkaloid-containing ants and mites constitute the majority of diet within all chemically-defended dendrobatids and some non-defended ones, although there is high intra- and inter-specific variation $(13,15,16)$. Consuming an alkaloid-rich diet while also acquiring enough lipids and protein for metabolism and reproduction can be challenging. In particular, lipids are important for gamete production and metabolic maintenance in amphibians $(10,17)$, and yet are a limiting resource among arthropod food webs (18). Chitinous arthropods, such as ants and mites have high levels of insoluble/indigestible carbohydrates (19), and therefore frequent ingestion is expected to incur a nutritional tradeoff (20). Although poison frog stomach content analyses have greatly aided our understanding of diet in the dendrobatid clade, how dietary preferences based on prey phenotype or frog alkaloid load have never been tested. Thus, nutritional analyses paired with prey selectivity assays are 
necessary to assess the possible tradeoffs between acquiring chemical defenses and necessary nutrients.

Here, we examined prey preference of Dyeing poison frogs (Dendrobates tinctorius). We tested the hypothesis that chemical defense acquisition, prey size and prey type influence dietary preferences in poison frogs. We first tested preference based on size within prey categories, as a study in the Malagasy Mantellidae poison frogs suggests a dietary preference towards smaller prey items (21), and because prey size is known as a crucial factor for dietary selectivity in frogs generally $(22,23)$. We predicted the frogs would show a greater preference towards smaller chitinous prey categories (ants, beetles), but larger versions of non-chinous prey (flies, larvae), as insect larvae tend to have higher protein and lipid content compared to chitinous adult arthropods (24). We next tested preference for prey taxonomic identity and nutritional value and predicted $D$. tinctorius would prefer ants, which make up the majority of poison frog stomach contents in the wild $(13,16,25)$. Finally, we tested whether chemical defense changes prey preference by experimentally manipulating alkaloid load and measuring prey selection. We expected frogs to prefer more nutrient-rich prey as they acquire alkaloids. Together, our work helps to fill the gap in our understanding of how prey size, type and nutritional quality affect the dietary choices of chemically defended predators.

\section{Methods}

\section{Animals}

Dendrobates tinctorius $(\mathrm{N}=20)$ were purchased from Josh's Frogs (Owosso, MI, USA) and housed in pairs in glass terraria with sphagnum moss, live philodendrons, shelters, egg laying sites, and a water pool. Frogs were fed three times per week with fruit flies dusted with vitamin supplements. Terraria were misted with water ten times per day and maintained in a 
temperature-controlled room with a $12 \mathrm{~h}: 12 \mathrm{~h}$ light-dark cycle immediately preceded and followed by a 10 min period of dim lighting to simulate dawn and dusk. The Institutional Animal Care and Use Committee at Stanford University approved all frog experiments (Protocol \#33839).

The arthropods used in this study are comparably sized to wild prey items (26), although they are not the same species, which are not commercially available. Four groups of arthropod prey of two sizes each were used in frog feeding assays as follows (large, small): Ants: Camponotus vicinus [7.0-10.0 mm, $\sim 5 \mathrm{mg}$ ], Linepithema humile [2.2-2.6 mm, $1.5 \mathrm{mg}]$, Flies: Drosophila hydei $[3.0 \mathrm{~mm}, \sim 2.5 \mathrm{mg}]$, Drosophila melanogaster [1.6 mm, $1.3 \mathrm{mg}$ ], Beetles:

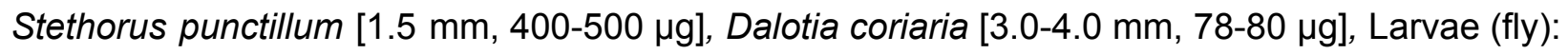
Callifora vomitoria [10 mm, 66 mg], Musca domestica [3-5 mm, $12 \mathrm{mg}](27,28)$. Ants were collected the morning of frog feeding trials on the Stanford University campus by sweeping ants off their nesting trees with a bristle brush into a clean ziploc bag. All beetles and larvae were purchased from online vendors (Arbico Organics: Tucson, Arizona, USA; Evergreen Growers Supply: Clackamas, Oregon, USA; Nature's Good Guys: Ventura County, California, USA; Speedyworm Bait Suppliers, Alexandria, Minnesota, USA). Live larvae were kept refrigerated at $4^{\circ} \mathrm{C}$ and neither fed nor hydrated to prevent them from pupating into adult flies. Flies were maintained at room temperature in 32 oz. plastic deli cups with aerated lids using fruit fly media (Josh's Frogs). Beetles were stored in 32 oz. plastic deli cups with aerated lids with packaging bedding and cotton balls soaked with a 1:1 table sugar:water solution. The beetles were misted with water three times per week and occasionally were fed grain mites (Acarus siro) sourced from the lids of mite-infested fly cultures. To our knowledge, none of the eight prey species chosen are chemically defended.

\section{Behavior}

All dietary preference assays were conducted in the same room where frogs are housed, in which temperature and humidity replicate conditions of their native habitats. One week before 
feeding trials began, all frogs were exposed to arthropod prey items six times over three weeks to reduce neophobia. Trials were conducted in a small transparent plastic bin $(33 \mathrm{~cm} \times 20 \mathrm{~cm} \times$ $12 \mathrm{~cm}$ ) stacked within an identical secondary bin with a layer of dried magnolia leaves to simulate a forest-floor environment while keeping the texture even throughout the arena. Inner sides of the arena were coated with Fluon ${ }^{\mathrm{TM}}$ liquid teflon (Bioquip Products Inc, Rancho Dominguez, CA, USA) to prevent the arthropod prey from escaping.

\section{Size-mediated dietary preference assay}

Adult frogs (11 female, 9 male; age unknown) were chosen at random and placed in the arena with 10 individual insects (five big, five small) of one of the given prey groups (ants, beetles, flies, or larvae). Each trial was conducted for $5 \mathrm{~min}$ and recorded with a GoPro camera (GoPro Inc, San Mateo, CA, USA) mounted above the arena. Each frog participated in one trial with each prey group and the order in which frogs and prey were tested was randomized. Intertrial intervals were roughly $10 \mathrm{~min}$ and the arena was emptied and wiped down with a moist paper towel during this time. Videos of all behavior trials were scored using BORIS (Behavior Observation Research Interaction Software) (29). The number of "eat" events and "attempt to eat" events were scored for each size prey item within a trial.

\section{Alkaloid feeding and taxon dietary preference assay}

Dietary preference trials were conducted to determine frog preference for different insect taxa and how this preference may change with chemical defense (Figure 1A). Only female frogs $(\mathrm{N}=10$, age unknown) were used in this behavioral assay as male frogs consistently exited the arena before trial completion. Frogs were orally administered $15 \mu \mathrm{l}$ of a vehicle control solution ( $0.85 \%$ sodium chloride, $1 \%$ ethanol, $98.15 \%$ deionized water). One week later, frogs were chosen at random and placed in the arena with 20 individual insects based on preferences in the size trials described above: five large larvae (Callifora vomitoria), five small ants 
(Linepithema humile), five small beetles (Dalotia coriaria) and five small flies (Drosophila melanogaster). Each trial was conducted for 5 minutes and recorded with a GoPro camera mounted above the arena. The arena was emptied and wiped down with a moist paper towel between trials.

To test how preferences may change as frogs acquire chemical defenses, the same 10 frogs were orally administered $15 \mu \mathrm{l}$ of $0.01 \%$ Decahydroquinoline (DHQ) in vehicle solution three times over the course of one week. The following week, these "low-DHQ" frogs were re-tested in the taxon dietary preference trials described above. One week later, frogs were orally administered $15 \mu \mathrm{ll} 0.01 \% \mathrm{DHQ}$ three times per week over two consecutive weeks, representing a "high-DHQ" treatment. The following week, frogs were retested in a final preference trial. Previous work has established this alkaloid-feeding paradigm as appropriate in creating low and high DHQ groups $(30,31)$.

Each frog was assayed once at each toxicity level for a total of three trials. Some Videos could not be scored due to camera malfunction. Both ingestion and an attempt to pursue or ingest prey of each type were scored using BORIS software. The scorer was not aware of the treatment group at the time of scoring. 


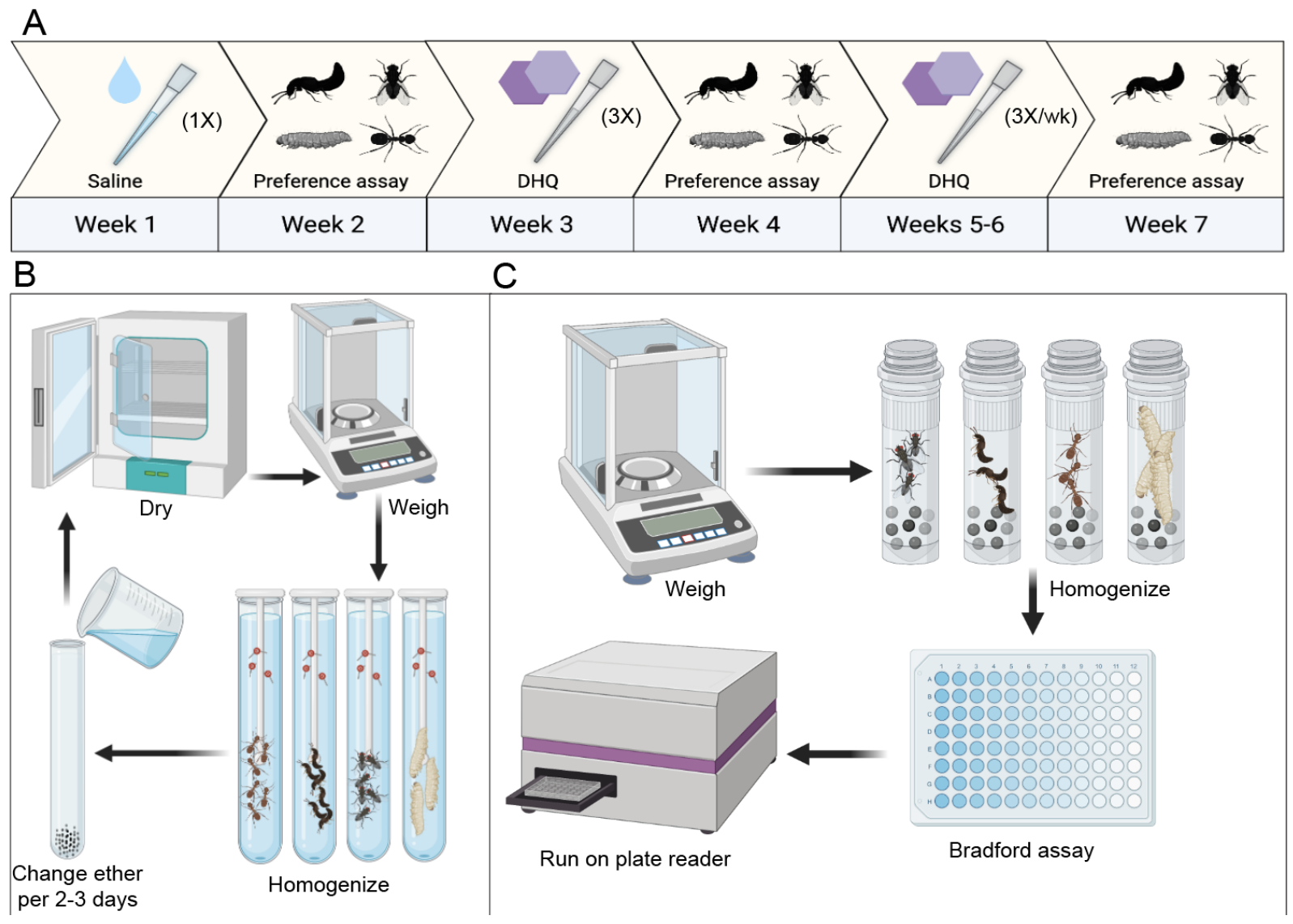

Figure 1: Experimental workflows of diet preference and nutritional assays. (A) The workflow of the alkaloid-mediated diet preference assay is depicted on a 7-week timeline. (B) Workflow of ether-soluble lipid quantification of prey items are shown. After the 6-8 day ether step, the arrow points to the drying and weighing steps, as they must be repeated to obtain lipid-free weight. (C) Workflow of the Bradford Protein assay of prey items are shown. Although our experiment used 5 replicates per prey group in lipid and protein assays, only single replicates are depicted here.

\section{Nutritional content assays}

Crude lipid content was quantified across the eight prey groups used in the dietary preference behavior experiments using an ether-soluble lipid extraction method (Figure 1B) (24). All arthropods were fresh-frozen at $-80^{\circ} \mathrm{C}$ and stored for $1-2$ weeks. After thawing, specimens were separated into five 1-2 $\mathrm{mL}$ biological replicates per prey group. The number of specimens used per prey type varied due to density and size. Each sample was placed in an incubator at $60^{\circ} \mathrm{C}$ until they were dried to a constant mass, defined as less than a 0.10 percent 
change after an additional 20 minutes of drying (24). One replicate per arthropod sample group was weighed once after 2 hours, and again after three hours, when a constant mass was reached for all prey groups except for larvae, which reached a constant mass after $\sim 12$ hours of drying. Once a constant mass was reached for all prey groups, the final mass was recorded and samples were placed in a glass culture tube filled with $5 \mathrm{ml}$ of petroleum ether (Thermofisher Scientific, Waltham, MA, USA) and ground with a Dounce Homogenizer. Specimens were then incubated in ether for 8 days at room temperature. Every two days during this period, each ether was carefully decanted from each tube to prevent loss of non-lipid mass and then replaced with fresh ether. Specimens were then left in their tubes uncovered for $\geq 24 \mathrm{~h}$ in a fume hood to allow for evaporative removal of the remaining ether. Samples were then placed into an incubator at $60^{\circ} \mathrm{C}$ for $\geq 3 \mathrm{~h}$ for additional drying. Once specimens were completely dried, they were weighed and lipid-free mass was subtracted from total mass, indicating the biological portion made up of ether-soluble lipids.

Crude proteins were extracted from each of the eight prey groups. All arthropods were fresh-frozen live at $-80^{\circ} \mathrm{C}$ and stored for $1-2$ weeks. Five replicates of $10-150 \mathrm{mg}$ of each arthropod type were put into $2 \mathrm{ml}$ tubes, each containing $2.4 \mathrm{~mm}$ stainless steel beads (Omni Life Science Inc, Raynham, Massachusetts, USA, SKU: 19-640) and $0.8 \mathrm{ml}$ of cold $1 \mathrm{x}$ phosphate-buffered saline (PBS, pH 7.4). Samples were homogenized at $4^{\circ} \mathrm{C}$ using a Beadmill 24 Homogenizer (Thermofisher Scientific) with the following settings: Speed in $\mathrm{m} / \mathrm{s}(\mathrm{S}): 4.5$, Number of cycles (C): 10, Cycle time $(T)$ : 30s, Interval paused between cycles (D): 10 s. Samples were then centrifuged at $2,000 \mathrm{rpm}$ at $4^{\circ} \mathrm{C}$ for five minutes. The supernatant containing the protein lysate was moved into a new $1.5 \mathrm{~mL}$ microfuge tube and stored for 1 week at $-80^{\circ} \mathrm{C}$. Proteins were then quantified using a Bradford Protein assay according to manufacturer's instructions (Pierce Coomassie Plus Bradford Protein Assay Reagent, Thermofisher Scientific). Samples and albumin standards were run in triplicate on a 96-well optical plate and quantified on a BioTek Synergy H1 96-well plate reader (Winooski, Vermont, USA). Absorbance was 
measured at $595 \mathrm{~nm}$ and an endpoint absorbance value was calculated for each standard and sample. Crude protein concentrations of arthropod samples were calculated based on the absorbance values of samples compared to the standard curve.

\section{Data analysis and visualization}

Statistical analyses were run in $\mathrm{R}$ version 4.1.1 using the glmmTMB package (32). To assess differences in large and small prey consumption, we fit zero-truncated generalized linear mixed models (GLMM) for each of the four prey assays (large vs. small ants, beetles, flies, larvae) based on a truncated Poisson distribution of the number of "eats" or "attempts" across all 19 frogs. To control for individual variation in the subjects, frog ID was used as a random effect, and since each frog differed in its total number of prey interactions across the four size preference assay categories, "total interactions with prey" was used as an offset in order to account for these differences in consumption. Sex was also used as a covariate because of previous knowledge of differences in diet between male and female dendrobatids (33).

To assess differences of prey interactions across control, low-DHQ, and high-DHQ groups, we used our taxonomic prey preference assay data to fit a zero-truncated generalized linear mixed models (GLMM) to compare the number of prey interactions for each prey type: ants, beetles, flies, larvae based on a truncated Poisson distribution of the number of "eats" or "attempts" across the 10 female frogs that were assayed. To account for individual variation in the subjects, frog ID was used as a random effect, and since each frog differed in its total number of prey interactions across the four prey choices, we used "total interactions with prey" as an offset in order to account for these differences in consumption. To check for differences in the general structure of frog diet categories across the three groups, we performed a permutational multivariate analysis of variance (PERMANOVA) on Bray-Curtis dissimilarities. We used a zero-truncated GLMM (glmmTMB package, R version 4.1.1) to compare total frog interactions (eats or attempts of all prey items) across the three groups: control, low and high 
DHQ. The model was based on a truncated Poisson distribution as described above. To control for repeated measures in the subjects, frog ID was again used as a random effect. P-values were adjusted using the Benjamini-Hochberg procedure to correct for multiple hypothesis testing across all dietary preference and nutritional analyses. Data were visualized with boxplots and barplots created using the package 'ggplot2' in $\mathrm{R}$ version 4.1 .1 and infographics were created with images from BioRender.com.

\section{Results}

Frogs prefer smaller prey items but large larvae

Overall, frogs interacted (ate or attempted) more with the smaller versions of prey items (Figure 2). Frogs interact more with small compared to large flies (GLMM, Z: 16.02, BH-adjusted $\mathrm{p}<0.0001)$ and small compared to large beetles (GLMM, Z: 2.558, BH-adjusted $p=0.021$ ).

There was no preference for small versus large ants or larvae within this behavioral assay (Generalized linear mixed model (GLMM), Ants: Z: 0.844, BH-adjusted p = 0.477; Larvae: Z: $0.712, \mathrm{BH}$-adjusted $\mathrm{p}=0.477$ ). The relative frequency of prey interactions did not differ between prey groups (Kruskal-Wallis chi-squared $=2.6556, \mathrm{df}=3, \mathrm{p}$-value $=0.448)$. 

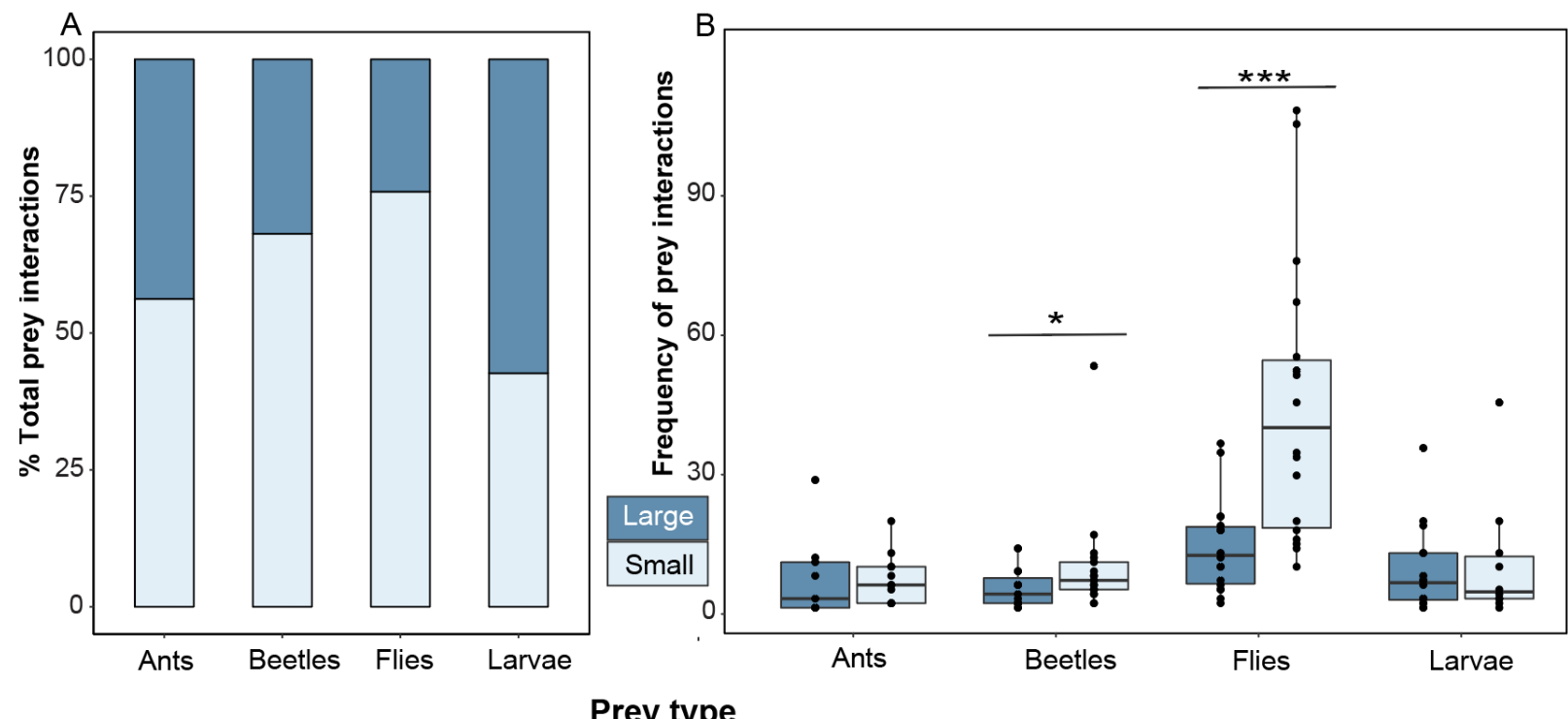

Figure 2. Dietary choices based on prey size. Dendrobates tinctorius frogs mainly interacted with (ate or attempted) small prey items in prey size preference assays. Each frog was presented with one prey group at a time and given the choice of small and large versions of ants, beetles, flies and larvae. (A) Percent breakdown of all interactions across prey groups are plotted in a stacked bar chart and (B) the frequencies of individual frog interactions among large and small prey are visualized as box plots, where each dot represents one frog.

\section{Alkaloid ingestion changes dietary preference}

When given the choice between multiple prey taxa, frogs without DHQ interact more with larvae than any other prey item (GLMM, Z: 4.95, p<0.00001), but there are significant preferences among other three prey categories. However, frogs change their dietary preferences as they acquire $\mathrm{DHQ}$. Although the three groups did not differ in their interaction frequency with prey types when compared simultaneously (PERMANOVA; F: 0.8932, p= 0.470), high DHQ frogs interact more with larvae compared to control and low DHQ frogs (GLMM, Z: $-2.598, \mathrm{BH}$-adjusted $\mathrm{p}=0.036)$, although interactions with larvae were extremely variable across groups. There were no differences found among ant (GLMM, Z: 0.326, BH-adjusted $p=0.744)$, 
fly (GLMM, Z: 0.879, $p=0.379, \mathrm{BH}$-adjusted $p=0.744)$, or beetle interactions $(\mathrm{z}:-0.409$, BH-adjusted p: 0.744).
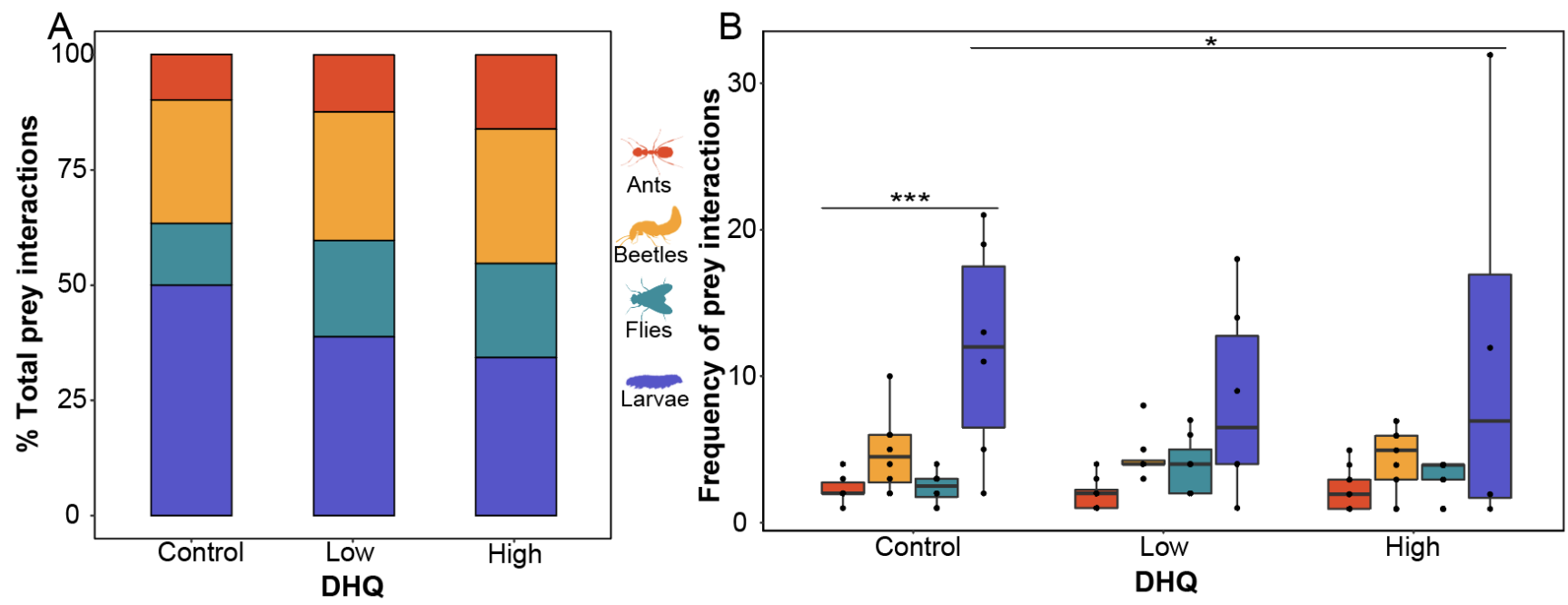

Figure 3. Frog prey preference changes with increasing chemical defense (A) Percent breakdown of all prey interactions (eats or attempts) across DHQ-fed and vehicle control groups are plotted in a stacked bar chart and (B) the raw frequencies of prey interactions among frog toxicity groups are visualized as box plots to show the variation of prey interactions across individuals, where each dot represents a frog.

Prey items differ in lipid and protein content

All eight prey species were evaluated for two important dietary components: lipids and proteins (Figure 4). Overall, lipid content differed across all prey types (Kruskal-Wallis $\mathrm{X}^{2}=$ 29.564, $\mathrm{df}=7, \mathrm{p}$-value $=0.0001)$. Small ants, beetles and larvae had a higher proportion of lipids than their larger counterparts, while large flies had a higher proportion of lipids than small flies (Figure 4, Table 1). Protein content also differed across species (Kruskal-Wallis $X^{2}=29.206$, $\mathrm{df}=7, \mathrm{p}$-value $=0.0001$, where large larvae have more protein than most prey items, followed by small beetles, which have more protein than small or large ants and flies (Figure 4, Table 2). Protein content did not differ within taxa for large compared to small prey. In summary, small ants have the most lipids, while large larvae have the most protein of all other prey categories. 

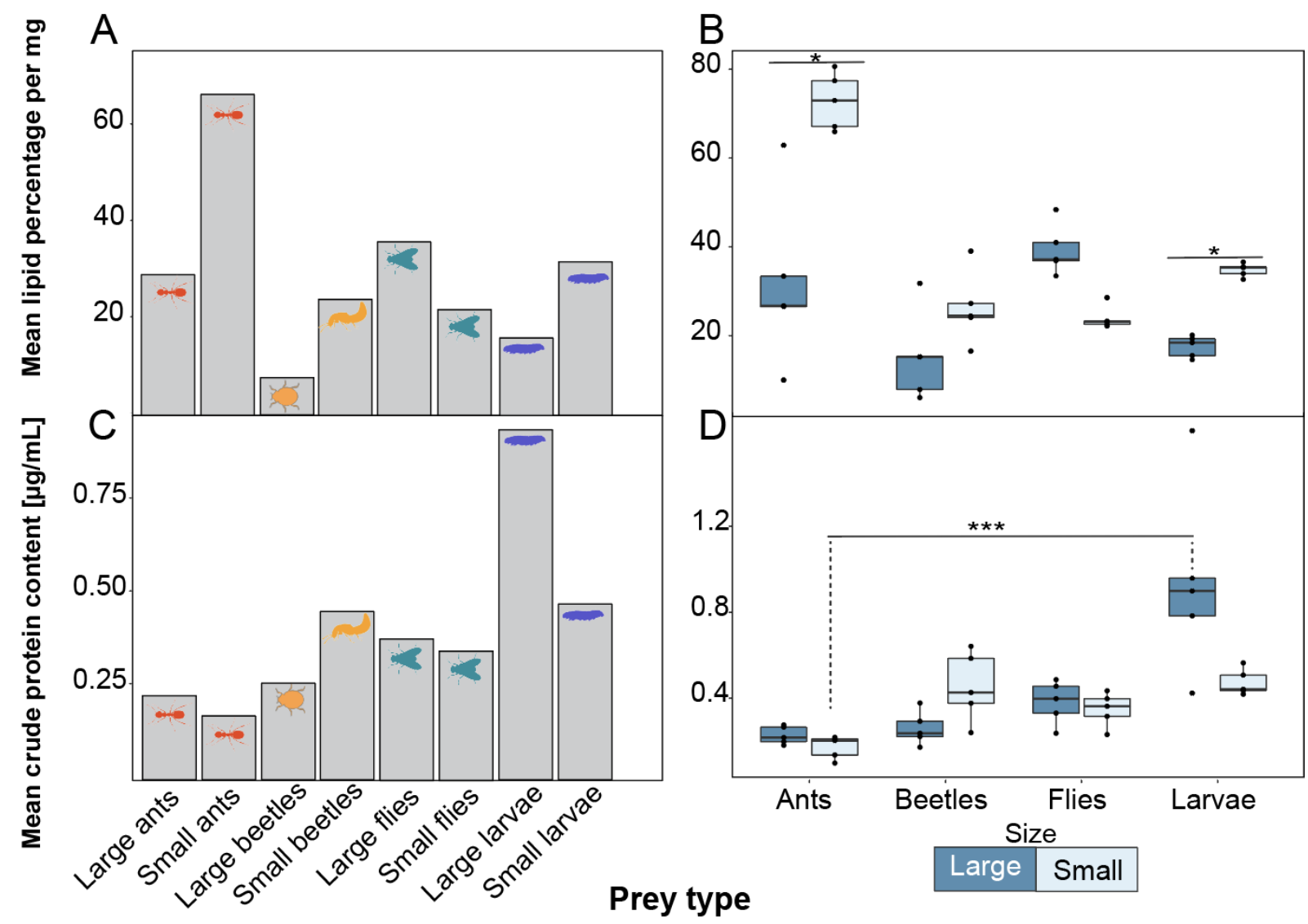

Figure 4. Nutritional content of prey from dietary preference assays. (A) Average crude lipid contents across replicates of the eight arthropod species are depicted in a bar chart, and (B) Variation of these values across replicates is shown in a box plot, where each dot represents a replicate. (C) Average crude protein content across replicates of the eight arthropod species are depicted in a bar chart, and (D) variation of these values across replicates is shown in a box plot, where each dot represents a replicate.

Table 1. Differences in crude lipid content (\% dry weight, mg) between arthropods. Statistics of arthropod taxa differences in crude lipid content using Kruskal-Wallis test with a Dunn Multiple Comparison Posthoc test. P-values were adjusted using the Benjamini-Hochberg procedure to correct for multiple hypothesis testing

\begin{tabular}{|c|c|c|c|}
\hline Comparison & $\mathbf{Z}$ & Raw P & BH-adjusted P \\
\hline large larvae - small ants & -4.0307 & 0.0001 & 0.0008 \\
\hline large beetles - small ants & -4.1659 & 0.0000 & 0.0009 \\
\hline small ants - small flies & 3.1109 & 0.0019 & 0.0131 \\
\hline large flies - large larvae & 3.0298 & 0.0025 & 0.0137 \\
\hline
\end{tabular}




\begin{tabular}{|c|c|c|c|}
\hline large beetles - large flies & -3.1650 & 0.0016 & 0.0145 \\
\hline small ants - small beetles & 2.6240 & 0.0087 & 0.0348 \\
\hline large beetles - small larvae & -2.6240 & 0.0087 & 0.0406 \\
\hline large ants - small ants & -2.4617 & 0.0138 & 0.0430 \\
\hline large larvae - small larvae & -2.4887 & 0.0128 & 0.0449 \\
\hline large flies - small flies & 2.1100 & 0.0349 & 0.0976 \\
\hline
\end{tabular}

Table 2. Differences in crude protein content (conc $[\mu \mathrm{g} / \mathrm{ml}])$ between arthropod prey.

Statistics of arthropod taxa differences in crude protein content using Kruskal-Wallis test with a Dunn Multiple Comparison Posthoc test. P-values were adjusted using the Benjamini-Hochberg procedure to correct for multiple hypothesis testing.

\begin{tabular}{|c|c|c|c|}
\hline Comparison & Z & Raw P & $\begin{array}{c}\text { BH-adjus } \\
\text { ted } \mathbf{P}\end{array}$ \\
\hline large larvae - small ants & 4.1932 & 0.0000 & 0.0008 \\
\hline large ants - large larvae & -3.5709 & 0.0004 & 0.0050 \\
\hline small ants - small larvae & -3.4086 & 0.0007 & 0.0061 \\
\hline large beetles - large larvae & -3.1246 & 0.0018 & 0.0125 \\
\hline small ants - small beetles & -2.9217 & 0.0035 & 0.0195 \\
\hline large ants - small larvae & -2.7864 & 0.0053 & 0.0249 \\
\hline large flies - small ants & 2.5159 & 0.0119 & 0.0475 \\
\hline large ants - small beetles & -2.2995 & 0.0215 & 0.0668 \\
\hline large beetles - small larvae & -2.3401 & 0.0193 & 0.0675 \\
\hline large larvae - small flies & 2.1507 & 0.0315 & 0.0882 \\
\hline
\end{tabular}




\section{Discussion}

We tested the hypothesis that frog chemical defenses and prey traits like size and nutritional value would influence diet choices in poison frogs. We expected laboratory $D$. tinctorius to prefer small prey items, reflecting their wild diet, which was generally true. However, we were surprised to find frogs did not prefer ants over other prey items, as these frogs are thought to have a dietary specialization on ants and mites in the wild. Rather, D. tinctorius generally prefers prey items with high lipid and protein content and frog alkaloid load can influence prey preferences. We discuss these laboratory results in the context of field studies in amphibians and the importance of replicating these studies under natural conditions in the future.

\section{Prey selectivity of arthropods}

Predators' ability to consume and obtain energy from prey is primarily limited by the prey size, making size an important factor in dietary selection (1). In our study, D. tinctorius frog dietary preference was assessed using prey size mediated assays, where frogs preferred small flies and beetles over large ones, with no preference for size in ants or larvae. Our findings are similar to a study conducted with Mantella aurantiaca poison frogs (Mantellidae), which have a slight preference for smaller prey items (21). We did not find a size preference for ants or larvae, which has been documented in Chiasmocleis mehelyi (Microhylidae) frogs that show a preference for small ants and avoidance of large ants relative to environmental abundance (23). However, we did not test ants from the natural range of $D$. tinctorius and testing such species may reveal other preferences based on size or other prey traits like alkaloid content. Additionally, these captive frogs have never consumed a wild-like diet, as they have been exclusively fed Drosophila melanogaster (small flies) until the start of this experiment, which 
may have influenced their dietary preferences. Despite these limitations, our study and previous literature show that prey size is a crucial factor for dietary choices of predators.

Taxonomic dietary preference was assayed using the most frequently chosen species (either large or small) from each prey group (small ants, small beetles, small flies, large larvae), and frogs preferred large larvae over other prey items. Although poison frogs consume a diverse array of non-ant prey items $(13,14,34)$, the stomach contents of $D$. tinctorius and many other chemically defended poison frogs in the wild are composed of over $50 \%$ ants $(13,26,34)$. Unexpectedly, we found that $D$. tinctorius frogs preferred larvae over other prey items tested, including ants, beetles, and flies. It is possible that frogs' foraging behavior would have been different when presented with ants from their natural habitat. For example, a field study with Chiasmocleis mehelyi (Microhylidae) frogs, which are hypothesized to sequester chemical defenses from their diet, showed preferential selection for ants over other arthropod categories $(23,35)$. Frogs in general can be selective predators, as the stomach contents of bufonid toads (Bufo cognatus \& Bufo woodsii) differ from local arthropod abundance (36). However, it may be prey availability that contributes to ant abundance in poison frog diets, as the frogs occupy microhabitats of the forest with high ant abundance. For example, a study that compared stomach contents of chemically defended Malagasy poison frogs (mantellidae) to environmental availability of arthropods found no significant differences between them, suggesting that their diet may reflect environmental availability rather than prey selectivity (37). Given the known importance of prey availability, we encourage future studies on organisms with diet-derived defenses to consider comparing environmental availability of prey items' effect on dietary patterns and preferences.

\section{Chemical defenses and prey preference}

While the acquisition of chemical defenses from diet can be physiologically burdensome, defended prey may also be nutritionally valuable. We tested the hypothesis that acquiring 
chemical defenses would change prey preferences and predicted that alkaloid-associated prey, such as ants, would become less desirable due to low nutritional value reported in the literature $(19,24)$. Contrary to our predictions, as frogs accumulated alkaloids they increased their preference for larvae, with high $\mathrm{DHQ}$ frogs showing a higher preference for larvae over low DHQ and control groups. As preference changes with defense consumption, it is possible that alkaloids can change foraging behavior as described in other animals. For example, in Red Knot birds (Calidris canutus), bodily levels of ingested toxins slow their feeding rates $(38,39)$. Another example comes from Mytilus mussels, where previous ingestion of toxins slows their toxin uptake rate and feeding rate $(40,41)$. Further, although not chemically defended themselves, possums consistently eat toxic, metabolically costly plants for their nutritional value (42). Based on these studies, a positive feedback relationship could be expected between frog alkaloid levels and ingestion of alkaloid-associated prey up to a physiological threshold of chemical burden. In the future, using ant species with alkaloids that poison frogs sequester may give more ecologically-relevant insight into how behavior changes with alkaloid uptake.

Behavior can change over time with repeated exposure to prey items (43-45). Our experimental design utilizes within-subject testing as frogs went from non-toxic to various loads of $\mathrm{DHQ}$ levels and thus repeated exposure and testing may instead reflect learning through experience rather than changes associated with alkaloid levels. We cannot currently verify that learning does not influence the prey preference patterns observed in our study. Although all eight prey species in the present study are not known to possess small-molecule alkaloids $(46,47)$, ants found in stomach frog contents carry alkaloids and are presumed to be the main dietary source for frog defenses $(12,48)$. We suggest that future studies should include alkaloid extractions on all prey items, as the possible presence of previously undetected defenses could influence preference assay results. Future studies on distinct groups of chemically defended and undefended frogs being presented with native prey items that contain alkaloids the frogs 
sequester are needed to disentangle these caveats. The results from our captive study suggest that this would be a worthwhile line of research to pursue in the future.

\section{Prey selectivity and nutritional content}

Dietary lipids and proteins are important for amphibian reproduction and survival. For example, the survival rate of Epidalea calamita toad tadpoles is positively correlated with protein consumption (49), and leopard frog tadpoles given a protein-rich diet are much more likely to overcome Batrachochytrium dendrobatidis infection (50), a disease which has ravaged frog populations globally (51). Lipids are also of known importance to frogs, specifically for metabolic demand and gamete production (17). A study that monitored whole-body lipid content in domestically-reared $H$. marmoratus taeniatus frogs showed a significant decrease in whole-body lipid content following their breeding period, suggesting that fat stores are quickly depleted through reproduction (52). Another study conducted in Rana tigrina found that frogs with small abdominal fat bodies showed significantly lower fecundity and decreased egg size than those with large abdominal fat bodies, and these differences were caused by diet quality (53). Given the importance of lipids and proteins to gamete production, metabolic demand, immunity and survival, nutrient content of prey items should be quantified when investigating factors that shape prey preference in amphibians.

In the current study, we assessed crude protein and lipid content of eight prey species, and unexpectedly found small ants were high in lipid content. Much of the literature describes ants as being composed primarily of insoluble fibers due to their chitinous exoskeletons $(18,19,54)$ On this basis we expected eating ants to impose a trade-off in poison frog foraging decisions between acquiring alkaloids versus nutrition. Yet, there are very few studies examining ant nutritional value, although our ant lipid results are similar to one study assessing nutrient quality of small ant species, which report lipid contents of $40-60 \%$ (55). However, our small ant lipid results are substantially higher than the only study which examined lipid 
percentage of the same small ant species as used in our study, Linepithema humile, as they report lower lipid contents of $18-20 \%$ (56). However, the ants in that study were given strict feeding regimens for the purposes of studying behavioral changes associated with manipulated protein:carbohydrate ratios in the diet. Therefore, those ants are expected to have a different nutritional makeup than the ones in our experiment, which are sourced from the wild. We note that the ants used in this study likely lack alkaloids previously described in poison frogs and a fruitful future direction would be to measure lipid, protein, and alkaloid content from species within the $D$. tinctorius natural range. Lipid and protein content of large larvae (Calliphora vomitora) from our current study matched previously reported values (57). Overall, the relative lipid values among orders from our study (Diptera, Coleoptera, Hymenoptera) are quite similar to the only large scale study which quantified and compared lipid content across major arthropod orders (24). However, a recent review of the nutritional quality of insects for animal feed shows that both lipid and protein contents are remarkably variable across studies of all insect taxa, even within single species (58). More studies with larger sample sizes across a wider range of arthropods are necessary to understand their nutritional value as prey items.

Although arthropods are an important dietary component of many taxa $(57,58)$, there are a few studies which quantify lipid or protein content of individual arthropod species. The vast majority of studies which examine arthropod crude protein and lipid content are focused on the benefits of arthropod consumption for humans and domestic animals $(60,61)$, with little focus on wild animals' diets. Within our study, small ants and large larvae seem to be the most nutrient-rich of all prey items. Large larvae have the highest protein content per mg but are lipid-poor, while small ants have the highest lipid content but are protein-poor (Figure 3). Both sizes of beetles and flies have similar protein levels to one another, but flies had a higher lipid content than beetles. Therefore, a nutritional trade-off arises between the decision of $D$. tinctorius individuals to consume either lipid and protein-rich prey items in the presence of both. Assuming the small ants in wild poison frog diet possess similar lipid and protein levels to the 
small ants in the present study (Linepithema humilis), chemical defense acquisition may not signify a total nutritional tradeoff, given the lipid richness of small ants. However, we encourage longer-term studies to be conducted using a higher sample size, prey items which more accurately reflect poison frog wild diet, and a wider variety of poison frog species and alkaloids, since diets between defended and undefended species indeed vary (13).

Prey choice becomes more complex when considering highly proteinous prey, like larvae, in the presence of lipid-rich small ants, which frogs are likely to associate with chemical defenses. We expected a clearer-cut tradeoff between consuming ants, which have high levels of indigestible carbohydrates $(19,57)$ while missing out on the nutritional value of undefended prey. However, given the lipid richness of small ants and the ant-dependent nature dendrobatid defenses, we propose that poison frogs consume alkaloid-laden prey opportunistically, but are predisposed to interacting more with higher protein prey, considering that protein is a limiting resource in arthropod food webs (18) and required for amphibian health $(49,50)$. Similarly, a particularly high demand for lipids should be expected in neotropical frogs that tend to breed for the majority of the year $(62,63)$ and should have a high lipid demand. Taken together, these wild diet studies paired with our results suggest that typical ant-rich wild poison frog stomach contents likely reflect a combination of their ant-rich habitats and dietary preferences, as proposed previously $(13,26,64)$.

\section{Conclusions}

We found that poison frogs prefer prey with high lipid and protein content and that alkaloid uptake influences dietary choices. The known importance of lipids to amphibian reproduction and survival taken together with our prey nutrient and preference assay results show that poison frogs may have nutritionally benefitted from a dietary specialization on ants before they evolved an ability to acquire chemical defenses from them. We suggest that innate prey preferences, the nutritional value of prey and prey availability are all important for our 
understanding of how dietary alkaloid sequestration evolved multiple times within the Dendrobatidae clade. The influence of nutritional value on dietary choices is essential for understanding the evolution of acquired chemical defenses and niche partitioning across heterotrophs. Future studies should evaluate the ecological significance of our findings by investigating preference and nutritional content of prey items available to wild frogs across a larger geographical and taxonomic scale that includes defended and undefended species.

\title{
Acknowledgements
}

We thank all the frog caretakers that maintain our poison frog and tadpole laboratory colony and Dr. Marie-Therese Fischer and Aurora Alvarez-Buylla for feedback on early versions of this manuscript. We acknowledge that our work takes place on the ancestral and unceded land of the Muwekma Ohlone tribe.

\section{Funding}

This work was supported by the Pew Charitable Trusts and the New York Stem Cell Foundation to LAO. This work was also supported by a Student Research Grant from the Society for Animal Behavior and a graduate research fellowship awarded by the National Science Foundation to both NAM (DGE-1656518). LAO is a New York Stem Cell Foundation - Robertson Investigator.

\author{
Author contributions \\ Conceptualization: NAM and LAO \\ Methodology: NAM and LAO \\ Formal Analysis: NAM \\ Investigation: NAM, RD, AAB \\ Resources: NAM and LAO \\ Data Curation: NAM \\ Writing - original draft preparation: NAM and LAO \\ Writing - review and editing: RD \\ Visualization: NAM
}


Supervision: LAO

Project administration: LAO

Funding acquisition: LAO and NAM

\section{References}

1. Emlen JM. The Role of Time and Energy in Food Preference. Am Nat. 1966 Nov;100(916):611-7.

2. Hutchinson DA, Savitzky AH, Burghardt GM, Nguyen C, Meinwald J, Schroeder FC, et al. Chemical defense of an A sian snake reflects local availability of toxic prey and hatchling diet. J Zool. 2013 Apr;289(4):270-8.

3. Weldon PJ. Avian chemical defense: Toxic birds not of a feather. Proc Natl Acad Sci. 2000 Nov 21;97(24):12948-9.

4. Gregory PT. Responses of Natricine Snakes to Predatory Threat: A Mini-Review and Research Prospectus. J Herpetol. 2016 Jun;50(2):183-95.

5. Fordyce JA, Nice CC. ANTAGONISTIC, STAGE-SPECIFIC SELECTION ON DEFENSIVE CHEMICAL SEQUESTRATION IN A TOXIC BUTTERFLY. Evolution. 2008 Jul;62(7):1610-7.

6. Smyth RR, Tallamy DW, Renwick JAA, Hoffmann MP. Effects of age, sex, and dietary history on response to cucurbitacin in Acalymma vittatum. Entomol Exp Appl. 2002 Jul;104(1):69-78.

7. Whitney TD, Sitvarin MI, Roualdes EA, Bonner SJ, Harwood JD. Selectivity underlies the dissociation between seasonal prey availability and prey consumption in a generalist predator. Mol Ecol. 2018 Apr;27(7):1739-48.

8. Skelhorn J, Rowe C. Predators' Toxin Burdens Influence Their Strategic Decisions to Eat Toxic Prey. Curr Biol. 2007 Sep;17(17):1479-83.

9. Wiggins NL, McArthur C, Davies NW. Diet switching in a generalist mammalian folivore: fundamental to maximising intake. Oecologia. 2006 Apr;147(4):650-7.

10. Brenes-Soto A, Dierenfeld ES, Muñoz-Saravia A, Janssens GPJ. No longer a leap in the dark: the importance of protein as an energy source in amphibians. Wildl Biol [Internet]. 2019 Sep 18 [cited 2021 Dec 8];2019(1). Available from:

https://bioone.org/journals/wildlife-biology/volume-2019/issue-1/wlb.00551/No-longer-a-I eap-in-the-dark--the-importance/10.2981/wlb.00551.full

11. Bolton SK, Dickerson K, Saporito RA. Variable Alkaloid Defenses in the Dendrobatid Poison Frog Oophaga pumilio are Perceived as Differences in Palatability to Arthropods. J Chem Ecol. 2017 Mar;43(3):273-89.

12. Hovey KJ, Seiter EM, Johnson EE, Saporito RA. Sequestered Alkaloid Defenses in the Dendrobatid Poison Frog Oophaga pumilio Provide Variable Protection from Microbial Pathogens. J Chem Ecol. 2018 Mar;44(3):312-25.

13. Darst CR, Menendez-Guerrero PA, Coloma LA, Cannatella DC. Evolution of Dietary Specialization and Chemical Defense in Poison Frogs (Dendrobatidae): A Comparative Analysis. :14.

14. Santos JC, Coloma LA, Cannatella DC. Multiple, recurring origins of aposematism and diet specialization in poison frogs. Proc Natl Acad Sci. 2003 Oct 28;100(22):12792-7. 
15. Valderrama-Vernaza M, Ramírez-Pinilla MP, Serrano-Cardozo VíH. Diet of the Andean Frog Ranitomeya virolinensis (Athesphatanura: Dendrobatidae). J Herpetol. 2009 Mar;43(1):114-23.

16. McGugan JR, Byrd GD, Roland AB, Caty SN, Kabir N, Tapia EE, et al. Ant and Mite Diversity Drives Toxin Variation in the Little Devil Poison Frog. J Chem Ecol. 2016 Jun;42(6):537-51.

17. Fitzpatrick LC. Life History Patterns of Storage and Utilization of Lipids for Energy in Amphibians. Am Zool. 1976 Nov;16(4):725-32.

18. Wilder SM, Norris M, Lee RW, Raubenheimer D, Simpson SJ. Arthropod food webs become increasingly lipid-limited at higher trophic levels. Jordan F, editor. Ecol Lett. 2013 Jul;16(7):895-902.

19. James B. McClintock. On estimating energetic values of prey: implications in optimal diet models. Oecologia. 1986;70(1):161-2.

20. Simon MP, Toft CA. Diet Specialization in Small Vertebrates: Mite-Eating in Frogs. Oikos. 1991 Jun;61(2):263.

21. Vences M, Glaw F, Zapp C. Mageninhaltsanalysen bei madagassischen Fröschen der Gattungen Tomopterna, Aglyptodactylus, Boophis und Mantidactylus (Anura: Ranidae). :8.

22. Ingle D, Cook J. The effect of viewing distance upon size preference of frogs for prey. Vision Res. 1977 Jan;17(9):1009-13.

23. Meurer W, Gonçalves FG, Bovendorp RS, Percequillo AR, Bertoluci J. Diet Electivity and Preferences for Food Resources in Chiasmocleis leucosticta (Anura: Microhylidae). J Herpetol [Internet]. 2021 Sep 27 [cited 2022 Jan 3];55(4).

24. Lease HM, Wolf BO. Lipid content of terrestrial arthropods in relation to body size, phylogeny, ontogeny and sex. Physiol Entomol. 2011 Mar;36(1):29-38.

25. Santos JC, Tarvin RD, O'Connell LA. A Review of Chemical Defense in Poison Frogs (Dendrobatidae): Ecology, Pharmacokinetics, and Autoresistance. In: Schulte BA, Goodwin TE, Ferkin MH, editors. Chemical Signals in Vertebrates 13 [Internet]. Cham: Springer International Publishing; 2016 [cited 2020 Jan 10]. p. 305-37. Available from: http://link.springer.com/10.1007/978-3-319-22026-0_21

26. Moskowitz NA, Dorritie B, Fay T, Nieves OC, Vidoudez C, 2017 Biology Class CRL, et al. Land use impacts poison frog chemical defenses through changes in leaf litter ant communities. Neotropical Biodivers. 2020 Jan 1;6(1):75-87.

27. Tourtois J, Grieshop M. Susceptibility of Dalotia coriaria (Kraatz) (Coleoptera: Staphylinidae) to Entomopathogenic Nematodes (Rhabditida: Heterorhabditidae and Steinernematidae). Insects. 2015 Mar 18;6(1):224-35.

28. Kalra B, Parkash R. Sex-specific divergence for body size and desiccation-related traits in Drosophila hydei from the western Himalayas. Comp Biochem Physiol A Mol Integr Physiol. 2014 Nov;177:1-10.

29. Friard O, Gamba M. BORIS : a free, versatile open-source event-logging software for video/audio coding and live observations. Fitzjohn R, editor. Methods Ecol Evol. 2016 Nov;7(11):1325-30.

30. Alvarez-Buylla A, Payne CY, Vidoudez C, Trauger SA, O’Connell LA. Molecular physiology of pumiliotoxin sequestration in a poison frog [Internet]. Physiology; 2020 Nov 
[cited 2022 Jan 3]. Available from:

http://biorxiv.org/lookup/doi/10.1101/2020.11.03.367524

31. O'Connell LA, LS50: Integrated Science Laboratory Course, O'Connell JD, Paulo JA, Trauger SA, Gygi SP, et al. Rapid toxin sequestration modifies poison frog physiology. J Exp Biol. 2021 Feb 1;224(3):jeb230342.

32. Brooks M E, Kristensen K, Benthem K J ,van, Magnusson A, Berg C W, Nielsen A, et al. glmmTMB Balances Speed and Flexibility Among Packages for Zero-inflated Generalized Linear Mixed Modeling. R J. 2017;9(2):378.

33. Donnelly MA. Feeding Patterns of the Strawberry Poison Frog, Dendrobates pumilio (Anura: Dendrobatidae). Copeia. 1991 Aug 1;1991(3):723.

34. Born M, Bongers F, Poelman EH, Sterck FJ. Abrigos durante a estação seca e mudanças na dieta do sapo-veneno-de-flecha Dendrobates tinctorius (Anura: Dendrobatidae). Phyllomedusa J Herpetol. 2010 Jul 1;9(1):37.

35. Díaz JA. Dietary selectivity and sexual size dimorphism of Chiasmocleis mehelyi (Anura: Microhylidae) in a Cerrado area of southwest Brazil. :7.

36. Flowers MA, Graves BM. Prey Selectivity and Size-Specific Diet Changes in Bufo cognatus and B. woodhousii during Early Postmetamorphic Ontogeny. J Herpetol. 1995 Dec;29(4):608.

37. Woodhead C, Vences M, Vieites DR, Gamboni I, Griffiths RA. Specialist or generalist? Feeding ecology of the Malagasy poison frog Mantella aurantiaca. :13.

38. van Gils JA, van der Geest M, Leyrer J, Oudman T, Lok T, Onrust J, et al. Toxin constraint explains diet choice, survival and population dynamics in a molluscivore shorebird. Proc R Soc B Biol Sci. 2013 Jul 22;280(1763):20130861.

39. Oudman T, Onrust J, de Fouw J, Spaans B, Piersma T, van Gils JA. Digestive Capacity and Toxicity Cause Mixed Diets in Red Knots That Maximize Energy Intake Rate. Am Nat. 2014 May;183(5):650-9.

40. Moroño A, Franco J, Miranda M, Reyero MI, Blanco J. The effect of mussel size, temperature, seston volume, food quality and volume-specific toxin concentration on the uptake rate of PSP toxins by mussels (Mytilus galloprovincialis Lmk). J Exp Mar Biol Ecol. 2001 Feb;257(1):117-32.

41. Navarro JM, Contreras AM, Chaparro ÓR. Short-term feeding response of the mussel Mytilus chilensis exposed to diets containing the toxic dinoflagellate Alexandrium catenella. Rev Chil Hist Nat [Internet]. 2008 Mar [cited 2020 Jan 22];81(1). Available from:

http://www.scielo.cl/scielo.php?script=sci_arttext\&pid=S0716-078X2008000100004\&Ing= en\&nrm=iso\&tlng=en

42. Wiggins NL, McArthur C, Davies NW, McLean S. Behavioral Responses of a Generalist Mammalian Folivore to the Physiological Constraints of a Chemically Defended Diet. J Chem Ecol. 2006 Jun;32(6):1133-47.

43. Eide NE, Eid PM, Prestrud P, Swenson JE. Dietary responses of arctic foxes Alopex lagopus to changing prey availability across an Arctic landscape. Wildl Biol. 2005 Jun;11(2):109-21.

44. Greenlees MJ, Phillips BL, Shine R. Adjusting to a toxic invader: native Australian frogs learn not to prey on cane toads. Behav Ecol. 2010;21(5):966-71. 
45. Caton SJ, Ahern SM, Remy E, Nicklaus S, Blundell P, Hetherington MM. Repetition counts: repeated exposure increases intake of a novel vegetable in UK pre-school children compared to flavour-flavour and flavour-nutrient learning. Br J Nutr. 2013 Jun 14;109(11):2089-97.

46. Attygalle $A B$, Morgan ED. Chemicals from the glands of ants. Chem Soc Rev. 1984;13(3):245.

47. Kishi Y, Parker J. Cell type innovation at the tips of the animal tree. Curr Opin Genet Dev. 2021 Aug;69:112-21.

48. Daly JW. The chemistry of poisons in amphibian skin. Proc Natl Acad Sci. 1995 Jan 3;92(1):9-13.

49. Martins FMS, Oom M do M, Rebelo R, Rosa GM. Differential effects of dietary protein on early life-history and morphological traits in natterjack toad ( Epidalea calamita ) tadpoles reared in captivity: Differential Effects of Diet on Tadpoles. Zoo Biol. 2013 Jul;32(4):457-62.

50. Venesky MD, Wilcoxen TE, Rensel MA, Rollins-Smith L, Kerby JL, Parris MJ. Dietary protein restriction impairs growth, immunity, and disease resistance in southern leopard frog tadpoles. Oecologia. 2012 May;169(1):23-31.

51. Lips KR. Overview of chytrid emergence and impacts on amphibians. Philos Trans $R$ Soc B Biol Sci. 2016 Dec 5;371(1709):20150465.

52. Grafe TU, Schmuck R, Linsenmair KE. Reproductive Energetics of the African Reed Frogs, Hyperolius viridiflavus and Hyperolius marmoratus. Physiol Zool. 1992 Jan;65(1):153-71.

53. Girish S, Saidapur SK. Interrelationship between food availability, fat body, and ovarian cycles in the frog, Rana tigrina, with a discussion on the role of fat body in anuran reproduction. J Exp Zool. 2000 Apr 1;286(5):487-93.

54. Chapman RF. The Insects: Structure and Function. Cambridge University Press; 2012. 963 p.

55. Bernadou A, Hoffacker E, Pable J, Heinze J. Lipid content influences division of labour in a clonal ant. J Exp Biol. 2020 Jan 1;jeb.219238.

56. Kay AD, Zumbusch T, Heinen JL, Marsh TC, Holway DA. Nutrition and interference competition have interactive effects on the behavior and performance of Argentine ants. Ecology. 2010 Jan;91(1):57-64.

57. Redford $\mathrm{KH}$, Dorea JG. The nutritional value of invertebrates with emphasis on ants and termites as food for mammals. J Zool. 1984 Jul;203(3):385-95.

58. Miller MJ, Bermingham E, Turner BL, Touchon JC, Johnson AB, Winker K. Demographic consequences of foraging ecology explain genetic diversification in Neotropical bird species. Ruegg K, editor. Ecology Letters. 2021 Mar;24(3):563-71.

59. Bbosa T, Tamale Ndagire C, Muzira Mukisa I, Fiaboe KKM, Nakimbugwe D. Nutritional Characteristics of Selected Insects in Uganda for Use as Alternative Protein Sources in Food and Feed. Weintraub P, editor. J Insect Sci. 2019 Nov 1;19(6):23.

60. Sánchez-Muros M-J, Barroso FG, Manzano-Agugliaro F. Insect meal as renewable source of food for animal feeding: a review. J Clean Prod. 2014 Feb;65:16-27. 
61. Hussein M, Pillai VV, Goddard JM, Park HG, Kothapalli KS, Ross DA, et al. Sustainable production of housefly (Musca domestica) larvae as a protein-rich feed ingredient by utilizing cattle manure. Qiu X, editor. PLOS ONE. 2017 Feb 7;12(2):e0171708.

62. Morrison C, Hero J-M. Geographic variation in life-history characteristics of amphibians: a review. J Anim Ecol. 2003 Mar;72(2):270-9.

63. Sheridan JA. Reproductive variation corresponding to breeding season length in three tropical frog species. J Trop Ecol. 2009 Nov;25(6):583-92.

64. Ralph A Saporito, Thomas F Spande, H Martin Garraffo, Maureen A Donnelly. Arthropod Alkaloids in Poison Frogs: A Review of the 'Dietary Hypothesis.' HETEROCYCLES. 2009;79(1):277. 